\title{
Saccadic Adaptation in Chiari Type II Malformation
}

\author{
Michael S. Salman, James A. Sharpe, Moshe Eizenman, Linda Lillakas, \\ Teresa To, Carol Westall, Martin J. Steinbach, Maureen Dennis
}

\begin{abstract}
Background: Saccadic adaptation corrects errors in saccadic amplitude. Experimentally-induced saccadic adaptation provides a method for studying motor learning. The cerebellum is a major participant in saccadic adaptation. Chiari type II malformation (CII) is a developmental deformity of the cerebellum and brainstem that is associated with spina bifida. We investigated the effects of CII on saccadic adaptation. Method: We measured eye movements using an infrared eye tracker in 21 subjects with CII (CII group) and 39 typically developing children (control group), aged 8-19 years. Saccadic adaptation was induced experimentally using targets that stepped horizontally $12^{\circ}$ to the right and then stepped backward $3^{\circ}$ during saccades. Results: Saccadic adaptation was achieved at the end of the adaptation phase in participants in each group. Saccadic amplitude gain decreased by $6.9 \%$ in the CII group and $9.3 \%$ in the control group. The groups did not differ significantly $(\mathrm{p}=0.27)$. Amplitude gain reduction was significantly less in the CII participants who had multiple shunt revisions. Regression analyses revealed no effects of spinal lesion level, presence of nystagmus, or cerebellar vermis dysmorphology on saccadic adaptation. Conclusion: The neural circuits involved in saccadic adaptation appear to be functionally intact in CII.
\end{abstract}

RÉSUMÉ: Adaptation saccadique dans la malformation de Chiari de type II. Contexte : L'adaptation saccadique corrige les erreurs de l'amplitude saccadique. L'adaptation saccadique induite expérimentalement peut être utilisée pour étudier l'apprentissage moteur. Le cervelet participe de façon importante à l'adaptation saccadique. La malformation de Chiari de type II (CII) est une malformation du cervelet et du tronc cérébral qui est associée au spina bifida. Nous avons évalué les effets du CII sur l'adaptation saccadique. Méthodes : Nous avons mesuré les mouvements oculaires au moyen d'un oculomètre à infrarouge chez 21 sujets atteints de CII (groupe CII) et chez 39 enfants de 8 et 19 ans qui avaient un développement normal (groupe témoin). L'adaptation saccadique était induite expérimentalement au moyen de cibles qui se déplaçaient horizontalement de $12^{\circ}$ vers la droite avec retour de $3^{\circ}$ pendant les saccades. Résultats : L'adaptation saccadique était réussie à la fin de la phase d'adaptation chez les sujets des deux groupes. Le gain d'amplitude saccadique diminuait de 6,9\% dans le groupe CII et de 9,3\% dans le groupe témoin. Les groupes n'étaient pas significativement différents $(\mathrm{p}=0,27)$. La diminution du gain d'amplitude était significativement moindre chez les sujets CII qui avaient eu de multiples reprises chirurgicales de leur dérivation. Les analyses de régression n'ont pas montré d'effet du niveau de la lésion spinale, de la présence de nystagmus ou de la dysmorphologie du vermis cérébelleux sur l'adaptation saccadique. Conclusion : Les circuits nerveux impliqués dans l'adaptation saccadique semblent intacts au point de vue fonctionnel dans le CII.

Can. J. Neurol. Sci. 2006; 33: 372-378

Chiari type II malformation (CII) is a congenital structural deformity of the brainstem and cerebellum associated with spina bifida (SB). In CII, the posterior fossa is small and, as a result, its contents are distorted and compressed as they herniate through the tentorial incisura and the foramen magnum. Hydrocephalus occurs in over $85 \%$ of patients with CII..$^{1-4}$

Saccades are fast, orienting and conjugate eye movements. Saccadic inaccuracies occur naturally as a result of aging and disease. Saccadic adaptation corrects errors in saccadic amplitude in a process of motor learning. ${ }^{5}$ The cerebellum, in particular, vermis lobules VI and VII and the fastigial nuclei, participates in controlling saccadic amplitude accuracy, ${ }^{6,7}$ and in saccadic adaptation. ${ }^{6,8-10}$ Inactivation of cerebellar vermis lobules VI and VII, or the fastigial nucleus results in markedly dysmetric saccades. ${ }^{6}$ Ablation of lobules VI and VII in monkeys and lateral medullary infarcts in humans abolish saccadic adaptation. ${ }^{6,9,10}$

Vermis lobules VI and VII are structurally distorted in CII. ${ }^{2}$ In addition, children with CII have impairments in estimating the

From the Divisions of Neurology (MSS), Population Health Sciences (TT), Opthalmology and Vision Sciences (CW), and Psychology (MD), The Hospital for Sick Children, Toronto, ON; Divisions of Neurology (MSS, JAS), Vision Science Research Program (MSS, JAS, LL, MJS), University Health Network, and Department of Biomedical Engineering (ME), University of Toronto, Toronto, ON; Section of Pediatric Neurology (MSS), Children's Hospital, University of Manitoba, Winnipeg, MB, Canada.

Received February 24, 2006. AcCePted in final Form July 6, 2006. Reprint requests to: Michael S. Salman, Section of Pediatric Neurology, AE 108, Harry Medovy House, Children's Hosptial, 820 Sherbrook St., Winnipeg, Manitoba, R3A 1R9, Canada. 
duration of short-interval tones (around $400 \mathrm{~ms}$ ) and in producing rhythmic finger tapping. ${ }^{11}$ This suggests that children with CII have timing deficits that could impair saccadic adaptation, because saccadic adaptation is processed by the cerebellum and is thought to have its origin in a precisely timed signal from the cerebellum. . $^{2,13}$

Error in saccadic amplitude can be induced experimentally by changing the visual target location during a saccade. ${ }^{14,15}$ After as few as 150 trials in which the target location is changed during saccades, saccadic amplitude is adjusted to land closer to the new target position. ${ }^{16,17}$ Saccadic adaptation occurs in children. ${ }^{18}$

We have previously shown that saccades are typically normal in most children with CII. ${ }^{19}$ Little is known, however, about the effects of the deformity of CII on cerebellar motor learning. Specifically, the functional consequences of CII on saccadic adaptation had not been investigated in SB. In this study of saccadic adaptation in CII, we hypothesized that: 1) Saccadic adaptation is impaired in participants with CII. 2) The magnitude of saccadic adaptation in the CII group is less in participants with upper spinal level lesions, multiple shunt revisions, nystagmus, and more vermis deformity as measured on midsagittal brain MRI.

\section{METHODS}

Participants were selected from a cohort of patients who were participants in a spina bifida project, funded by the National Institute of Child Health and Human Development. Twenty-one children with SB myelomeningocele and CII with hydrocephalus were studied and their demographics have been discussed in detail elsewhere. ${ }^{19}$ Their age range was between 8 and 19 years. All had visual acuity of at least $20 / 40$ and a verbal or performance IQ of 70 or above. Exclusion criteria were nystagmus in the range of the eye movement task on clinical examination, paralytic strabismus, medication with drugs that might interfere with eye movements (e.g., sedatives or anti- seizure medications), acute illness from the effects of hydrocephalus in the CII group, ocular, psychiatric, or neurological disorders unrelated to CII.

Thirty-nine typically developing children served as controls and were recruited by local advertising. Demographics of the control and CII groups were comparable (Table). Written consent was obtained from participants or their legal guardian. Ethical approval for this project was obtained from the Research Ethics Boards at the Hospital for Sick Children and the University Health Network, and the study was in accord with the declaration of Helsinki guidelines.

Means and standard deviations for SB and control groups on a visually guided upper limb pursuit task were used to guide power calculations, ${ }^{20}$ and is discussed elsewhere. ${ }^{19}$ All participants completed the task except for one with CII.

Spinal lesion level in the CII group was determined from physical examination. Two groups were distinguished: Upper spinal lesion level group (T12 and above, $\mathrm{N}=6$ ), and lower spinal lesion level group (L1 and below, $\mathrm{N}=15) .{ }^{21}$ Upper spinal lesions are associated with worse outcome..$^{22,23}$

The number of shunt revisions in participants with CII was used as a surrogate marker for the cumulative effects of severely raised intracranial pressure. ${ }^{23,24}$ Three shunt groups were created. Group 1 had no shunt revisions, Group 2 had one shunt revision, and Group 3 had two or more shunt revisions. ${ }^{25,26}$

Eight participants were found to have gaze-evoked nystagmus that was clinically detectable only outside the range of the eye movement task. In seven of these participants, we found a low amplitude $\left(<2^{\circ}\right)$ gaze-evoked nystagmus on eye movement recording in the range of the eye movement tasks that was not detectable on clinical examination. The effect of nystagmus was investigated.

Nineteen participants with CII had artifact-free, brain MRI scans. The following were used as surrogate markers for cerebral and cerebellar dysmorphology in CII on midsagittal MRI:

Table: Demographic information of the control and Chiari type II malformation (CII) groups

\begin{tabular}{lll}
\hline & Control group & CII group \\
\hline Number of participants & $39(18 \mathrm{~F})$ & $21 \quad(10 \mathrm{~F}, 15$ had lower spinal lesion) \\
Age in years (SD) & $13.7(3.5)$ & $14.3(3.2)$ \\
Shunted hydrocephalus & 0 & $21 *(5$ had one shunt and no revisions, 9 had 1 shunt \\
Non-paralytic strabismus & 3 & revision, 7 had $\geq 2$ shunt revisions) \\
Past history of seizures & 2 & $10^{*}$ (7 with lower spinal lesion) \\
Nystagmus & 0 & 3 \\
Ambulatory & 39 & $8 *$ (6 with lower spinal lesion) \\
\hline
\end{tabular}

$* \mathrm{p} \leq 0.001$ on chi squared test

$\S$ Nystagmus present on clinical examination outside the range of the eye movement task 
(A)

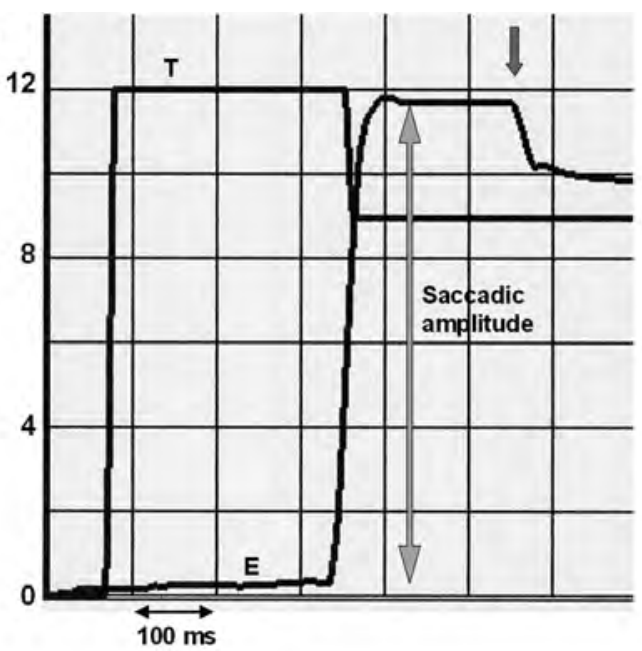

(B)



Figure 1: Horizontal saccades are shown in response to a visual target displacement of $12^{\circ}$ at $(A)$ an early and (B) a latter stage of adaptation, recorded from the right eye. Horizontal eye $(E)$ and target $(T)$ position traces are illustrated. Upward deflection represents rightward displacement of the eye. The vertical scale shows amplitude in degrees. Time is displayed on the $x$-axis in ms. Figure (A) shows the dynamics of the horizontal saccadic adaptation paradigm. During the initial saccade, the target is displaced back by $3^{\circ}$. Figure (B) shows a decrease in saccade amplitude (vertical double arrow) after 200 adaptive target steps, in comparison with Figure (A). Furthermore, the corrective leftward (downward arrow) saccade in (A) is no longer present in $(B)$.

intracranial fossa, posterior fossa, cerebellar vermis, vermis lobules I-V, and vermis lobules VI-VII areas, the longest longitudinal and transverse distances across the vermis, herniation distance and area below foramen magnum. ${ }^{2}$ All of these measurements are different in children with CII in comparison to typically developing children. For example, the posterior fossa is significantly smaller while the cerebellar vermis, vermis lobules I-V, and vermis lobules VI-VII areas, and the longest longitudinal and transverse distances across the vermis are significantly larger in children with CII in comparison to typically developing children. ${ }^{2}$

\section{EQUIPMENT AND PROCEDURES}

An infrared, video eye tracking system (El Mar Inc., Downsview, Ont., Canada) was used to record eye position and is described in more detail elsewhere. ${ }^{19}$ The system accuracy is $0.5^{\circ}$. The video image is sampled at $120 \mathrm{~Hz} \cdot{ }^{27}$ Head movements were recorded using a magnetic head tracker (Flock of Birds ${ }^{\mathrm{TM}}$, Ascension Technology Corp., Burlington, VT).

Each participant was seated on a chair with the eyes in the central mid orbital position, facing the center of a $45 \mathrm{~cm}$ monitor (Samsung, SyncMaster $900 \mathrm{NF}$ ), located $57 \mathrm{~cm}$ from the participant's cornea. The laboratory background was dark. The visual target was a $2-\mathrm{mm}$, white square light that subtended 12 minutes of arc. Stimulus luminance was $4.1 \mathrm{~cd} / \mathrm{m}^{2}$. The background monitor luminance was $0.001 \mathrm{~cd} / \mathrm{m}^{2}$. Participants' performance and alertness were monitored by a live video and by an oscilloscope display of eye movements to provide feedback during the task. Positions of each eye were calibrated with the fellow eye occluded at seven horizontal and seven vertical fixation light points. The participant's head was stabilized using a chin rest. Eyeglasses were removed. The uncorrected visual acuity was adequate for seeing and responding to the stimuli in all cases. The non-preferred eye was patched.

The saccadic adaptation task has been described previously. ${ }^{18}$ The visual target stepped at random time intervals ranging from 0.8 to 1.2 seconds. Targets stepped from random starting points on the mid horizontal $\mathrm{x}$-axis to points $12^{\circ}$ rightward and horizontal to the starting points. Fifty rightward target steps were presented in the pre-adaptive and post-adaptive saccade tasks in darkness. During the adaptive saccadic task, the same target steps were presented but the target position was moved $3^{\circ}$ backward (leftward) from the end of the step position when saccade eye velocity, which was computed on-line, reached $25 \%$. The backward step was triggered by the initial saccade and occurred during the saccade (Figure 1). Participants were unable to detect the target back-step when the laboratory was dark and when the monitor was covered by neutral density filters to conceal the screen light. Without the filters, some participants were aware of the target back-step in an earlier pilot study. Participants were presented with four successive blocks, each consisting of 50 rightward adaptive target steps. After the adaptive saccadic task, 50 rightward $12^{\circ}$ target steps were presented in the post-adaptive saccade task in complete darkness as described above.

\section{Processing of Eye Movement data}

The stimulus, head, and eye movements were digitized for off-line analysis and the velocity signals were filtered using a 5point Savitsky-Golay differentiator. Initial saccades were included for analyses if they had a minimum velocity of $100 \%$, if the eye position trace shifted $<0.5^{\circ}$ from baseline during the 


\section{(A)}

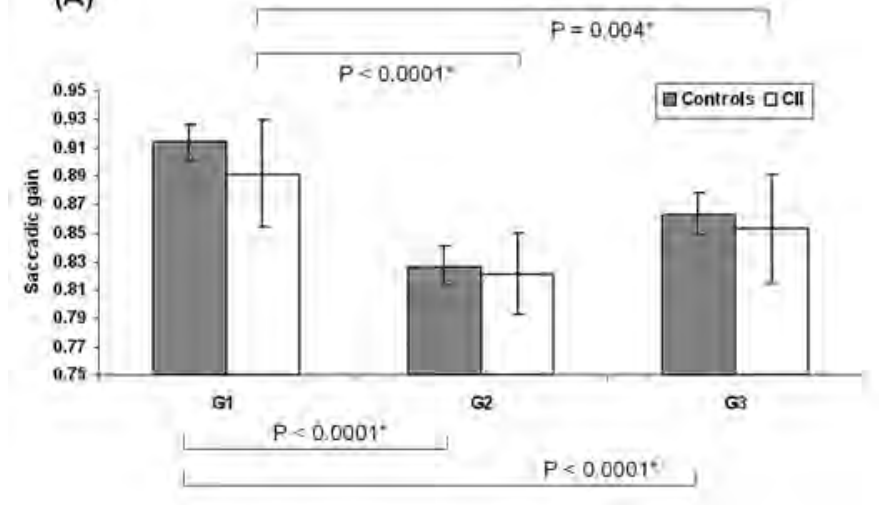

(B)



Figure 2: Reduction in saccadic amplitude gain is displayed following adaptation in both the control and Chiari type II malformation groups. A) Mean saccadic gain $( \pm 1 S E)$ at baseline (G1), end of adaptation (G2), and post-adaptation (G3). Baseline saccadic gain decreased significantly in each group following the adaptation task. B) Mean percentage reduction in saccadic amplitude gain from baseline ( $\pm 1 S E)$ at the end of adaptation (Ge) and after adaptation $(G p)$. The differences between the two groups were not significant.

$200 \mathrm{~ms}$ prior to target displacement up to saccade onset, and if saccades occurred within a latency of 70 to $450 \mathrm{~ms}$ as described previously. ${ }^{19}$ The beginning and end of saccades were marked automatically by interactive software when eye velocity exceeded $30 \%$. The data was displayed on a computer monitor so that the automatic markings could be edited by cursors. Adaptive saccades were included only if the target back-step occurred during the initial saccade. Leftward saccades were not measured. None of the saccades were associated with a horizontal head rotation $\geq 0.5^{\circ}$.

\section{ANALySES}

Analyses were done using a Statistical Package for Social Sciences. ${ }^{28}$ Normality of the data distribution was tested. ${ }^{29}$ Mean saccadic amplitude gains (G) for each participant, defined as saccade amplitude/ target amplitude, were calculated for all marked initial saccades at baseline (pre-adaptive task) (G1), at the last block of the saccadic adaptation task with back steps (end of the adaptive task) (G2), and after the adaptive task (postadaptive task) (G3). G2 and G3 were each compared with G1 using paired, two-tail Student t-tests for each group to test whether adaptation occurred. To quantify the amount of adaptation, the mean relative change in saccadic gain was calculated at the end of the adaptive task (Ge), [i.e., (G2-G1)/G1] and the post-adaptive task (Gp), [i.e., (G3-G1)/G1] for each participant, as described elsewhere. ${ }^{30,31}$ The overall mean values of Ge and Gp in the control and CII groups were compared using independent Student t-tests. G2 and G3 were compared within each group to test whether de-adaptation, defined as a significant increase in saccadic gain after the adaptation task on paired samples Student t-tests, occurred. This analysis was done to insure that the reduction in saccadic amplitude gain during the adaptation task was not caused by fatigue.
Variability (i.e., standard deviations) of saccadic amplitude gain by group was compared using Levene's test for equality of variances. ${ }^{29}$ To investigate intra-subject variability, the mean value of the standard deviations (SD) of saccadic gain for each participant was calculated for each group and compared using, independent Student t-tests. This analysis was performed because patients with cerebellar diseases are known to have larger saccadic amplitude variability than healthy controls.

Further variability in saccadic adaptation within the CII group based on spinal lesion level and nystagmus was investigated using independent 2-tailed t-tests. One-way ANOVA was used to compare the shunt groups. Two-tailed Pearson correlation tests for normally distributed data, and Spearman's correlation tests for non-parametric data, ${ }^{29}$ were used to correlate $\mathrm{Ge}$ with the number of adaptive saccades and with MRI parameters in the CII group. Further analyses were done using linear stepwise regression models. For all tests, significance was defined by $p$ values $<0.05$.

\section{RESUlts}

The number of saccades and saccadic amplitude gains at baseline, end of adaptation and post-adaptation had approximately normal distribution. The mean number of rightward saccades (SD) that met our strict inclusion criteria for analysis was 37 (10) at baseline in the CII Group. None of the participants noticed the back-step during the adaptive saccadic task when questioned at the end of the task.

\section{DIFFERENCES BETWEEN GROUPS}

Mean saccadic amplitude gain and the number of saccades were not significantly different between the control and CII groups at baseline, end of adaptation or post-adaptation tasks (Figure 2A). Saccadic adaptation, defined as significant 


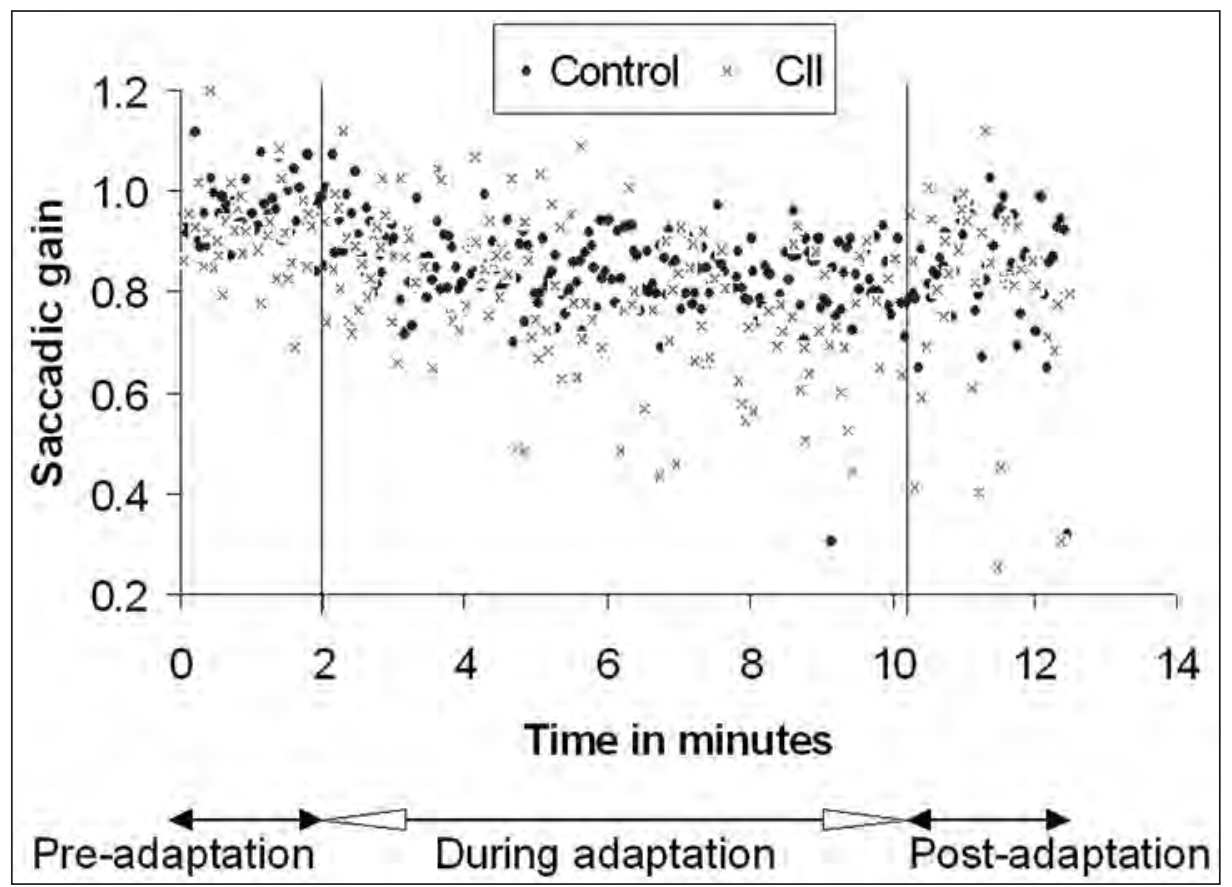

Figure 3: Time course of saccadic adaptation in a typically developing child and a child with Chiari type II malformation. Note the wider spread of the data (i.e., larger variability) in the child with CII. This larger variability in performance is seen in people with cerebellar dysfunction.

reduction in baseline gain following adaptation on paired samples Student t-tests $(\mathrm{p}<0.05)$, occurred in each group over the course of the task (Figure 2A). The time course of saccadic adaptation is shown in Figure 3.

The mean percentage in gain reduction from baseline, Ge $( \pm 1 \mathrm{SE})$ was $9.32(1.16) \%$ in the control group $(\mathrm{N}=39)$ and 6.92 (2.00)\% in the CII group $(\mathrm{N}=21)$ at the end of the adaptive task. The ideal decrease in gain would be $25 \%\left(3^{\circ}\right.$ back-step of $12^{\circ}$ target step). In other words, the control group attained $37.3 \%$ (9.32/ 25) and the CII group attained $27.7 \%$ (6.92/ 25) of the ideal gain reduction at the end of the adaptive task. These reductions in saccadic gains were not significantly different between the two groups $(p=0.27)$ (Figure $2 B)$. After the adaptive task, the mean percentage in gain reduction from baseline, Gp $( \pm 1 \mathrm{SE})$, was $-5.5(1.2) \%$ in the control group $(\mathrm{N}=$ $39)$ and $-4.4(2.0) \%$ in the CII group $(\mathrm{N}=20)$. The difference between the two groups was not significant $(p=0.62)$ (Figure 2B). De-adaptation, defined as a significant increase in saccadic gain after the adaptation task, occurred in the control group ( $\mathrm{p}$ $<0.0001)$ and approached significance in the CII group ( $\mathrm{p}=$ $0.059)$.

Between-group variability. When the variability (i.e., SD) of saccade gain in the control and CII groups was compared, saccadic gain was more variable in the CII group throughout the task. This increased variability in the CII group (SD 0.17) was significant only at baseline (control group SD 0.08, $\mathrm{p}=0.04$ ).
Intra-subject variability. There was a significantly larger intra-subject variability for saccadic gains at the end of adaptation in the CII group compared to the control group. Variability in gain in the CII group was 0.16 versus 0.13 in the control group, $p=0.037$. This can also be clearly seen in Figure 3. Intra-subject variability in baseline and post-adaptation saccades gain did not differ significantly between the two groups.

Variability within the CII group. There was no significant effect of age or gender on Ge. The number of adaptive saccades (i.e., the initial saccades that triggered the target back-steps) did not affect Ge. The CII participants had a mean of 128 saccades (SD 38) in response to back-stepped targets, while control participants had a mean of 139 saccades (SD 34). The difference was not significant.

Spinal lesion level. There was a trend for a higher mean saccadic gain at baseline in participants with upper spinal lesion level, $($ gain $=1.00$, SD 0.22) compared to participants with lower spinal lesion level (gain $=0.85$, SD 0.13, p = 0.056). However, no significant difference in adaptation was seen within the CII group by spinal lesion level.

Number of shunt revisions. There was a trend for a shunt group effect. $\mathrm{Ge}( \pm 1 \mathrm{SE})$ in the 'no shunt revision' group $(\mathrm{N}=5)$ was $-14.7(2.1) \%$ versus $-6.12(1.6) \%$ in the group requiring one shunt revision $(\mathrm{N}=9)$, and $-2.4(4.8) \%$ in the group that required greater than one shunt revisions $(\mathrm{N}=7),[\mathrm{F}(2,20)=3.21, \mathrm{p}=$ 
0.06, one-way ANOVA]. The magnitude of adaptation in the groups that had 'no shunt revision' or 'one shunt revision' was not significantly different from the control group. However, the magnitude of adaptation in the group that had "more than one shunt revision' was significantly different from the control group $(\mathrm{p}=0.047)$.

Nystagmus. Participants with nystagmus that was visible only in eccentric gaze did not differ significantly from participants without nystagmus, in mean baseline gain, mean number of adaptive saccades, or mean percentage gain reduction.

MRI parameters. No significant correlation was found between the change in gain from baseline, Ge, and MRI measurements in participants with CII.

Linear stepwise regression analyses also showed no correlation between Ge and age, gender, number of adaptive saccades, spinal lesion level, presence of nystagmus, number of shunt revisions, or MRI measurements.

\section{Discussion}

Most children with CII typically have intact saccades ${ }^{19}$ Our investigation has also shown that they are capable of adapting their saccades. This suggests that deformity of CII does not adversely affect ocular motor learning. In the current study, participants in the CII and control groups attained a comparable percentage in saccadic gain reduction with an equivalent number of saccades with target back-steps. The magnitude of reduction in saccadic amplitude was similar to values attained by some children, ${ }^{31}$ adults, and monkeys..$^{9,32}$ Therefore, the neural circuits required for saccadic adaptation are not adversely affected by the cerebellar deformity of CII in children with SB as young as eight years old. The spatial resolution of the eye tracker and its sampling rate of $120 \mathrm{~Hz}$ sufficed for comparing saccadic amplitude reduction. A relatively large target back-step of $3^{\circ}$ provided saccadic amplitude reduction that was detected clearly above the noise level of the eye tracker and ensured that the back-step was small enough to be undetected by participants.

Saccadic adaptation is reversible. ${ }^{9,16}$ Our results demonstrated that saccadic adaptation is also reversible in children with CII because saccadic gain increased after the adaptation task. Therefore, the reduction in saccadic amplitude gain at the end of the adaptation task was not caused by fatigue in this study. Variability in saccadic amplitude gain was larger in the CII group in comparison to the control group. Cerebellar dysfunction causes large variability in saccadic amplitude. ${ }^{6,33}$ Variability in visual attention tasks has also been reported in children with CII. ${ }^{34}$

The CII patients with upper spinal lesion level have greater deformity of posterior fossa structures than patients with lower spinal lesion level. ${ }^{22}$ We found no difference in the ability to adapt saccades based on spinal lesion level. However, baseline saccadic gain was larger in the upper compared to the lower spinal lesion level group. This relative hypermetria may signify more cerebellar dysfunction in patients with upper spinal lesion level. ${ }^{35,36}$

Shunt revisions are usually but not always done following shunt blockage. The number of shunt revisions is considered to be a surrogate marker for the cumulative effects of raised intracranial pressure on the developing brain. ${ }^{24}$ The amount of saccadic gain reduction in CII decreased with an increasing number of shunt revisions. Repeated expansion of the fourth ventricle by hydrocephalus might damage the fastigial nuclei, which lie at the apex of the fourth ventricle. The fastigial nuclei are necessary for saccadic adaptation. ${ }^{7}$

Recording eye movements in children is challenging, especially in those with chronic disability. Restricting the current study to participants with a verbal or performance IQ $>70$ selected higher functioning individuals with CII. The ability of mentally retarded individuals to adapt saccades remains unknown.

The major strengths of this study include the use of a noninvasive and well tolerated eye tracker system on children, the relatively large number of participants, and the use of saccadic adaptation as a model for studying ocular motor learning in children with a developmental anomaly of the hindbrain.

This investigation has shown for the first time that saccadic adaptation is intact in children with CII. Two adults with congenital cerebellar malformations, one with Dandy-Walker malformation and the other with cerebellar hypoplasia, were able to adapt their saccades, albeit to a lesser degree than eight healthy adult controls. ${ }^{33}$ The chronic, developmental, and congenital nature of CII may permit the dysmorphic cerebellum to re-calibrate eye movements to minimize errors. Alternatively, the cerebellar structures involved in saccadic adaptation may not be functionally affected by the deformity of CII. In CII, the vermis is compressed and its entire midsagittal surface area is enlarged. ${ }^{2}$ This enlargement involves lobules VI and VII, which participate in saccadic adaptation. ${ }^{8}$ The ability of the midsagittal vermis area to expand in all directions, because of its midline location, ${ }^{2}$ is postulated to leave its ability to process saccades, ${ }^{19}$ and saccadic adaptation intact. This proposition is supported by the current investigations' findings of the absence of correlation between saccadic adaptation and midsagittal vermis or lobules VI and VII area morphologies.

In contrast, saccadic adaptation is impaired in acquired cerebellar disorders. ${ }^{10,33,37}$ This, however, may depend on the natural history and chronicity of the disease, because Mezey and Harris, ${ }^{31}$ found that adaptation was preserved in children with resolved opsoclonus-myoclonus syndrome, despite the presumed cerebellar involvement.

Intact saccadic adaptation implies integrity of the neural structures that participate in this motor learning, which includes vermis lobules VI and VII. However, cerebellar hemisphere function is impaired in patients with CII; for example, individuals with SB have impaired perception of the duration but not the frequency of tones, ${ }^{11}$ as well as motor timing and speech deficits. ${ }^{38}$ Alternatively, saccadic adaptation in children with CII may be processed in structures outside the cerebellum. However, we found no published evidence for such a proposal.

Studies of skeletal motor learning in CII are consistent with the results of the ocular motor learning in the present study. Biasing of weight judgments, adaptation on reaching movements, and mirror drawing performance, which require a functional cerebellum, are normal in patients with CII. ${ }^{39,40}$

\section{ACKNOWLEDGMENTS}

The authors thank Dr. Daune L. MacGregor, Mrs. Irit Dror, Mr. Alan Blakeman for their support. We also thank the participants and their families for their time and effort. 
Supported by Research Training Competition Award, The Hospital for Sick Children (HSC); KidsAction; Spina Bifida and Hydrocephalus Association of Canada; Clinician Scientist Training Program Awards at HSC and Vision Science Research Program at Toronto Western Hospital; Bloorview MacMillan Hospital foundation grants (M.S. Salman); National Institute for Health grant "Spina bifida: Cognitive and neurobiological variability" (J. Fletcher, M. Dennis); CIHR of Canada Grants MT5404 and ME 5909 (J.A. Sharpe); NSERC of Canada A7664, The Sir Jules Thorn Charitable Trust, and the Krembil Family Foundation Grants (M.J. Steinbach); CIHR and the Ontario Ministry of Health and LongTerm Care Investigator Award (T. To).

\section{CONFLICT OF INTEREST}

Dr. M. Eizenman is the developer of the eye tracker. He has shares and interest in El Mar Inc., the manufacturer of the eye tracker.

\section{REFERENCES}

1. Gilbert JN, Jones KL, Rorke LB, Chernoff GF, James HE. Central nervous system anomalies associated with meningomyelocele, hydrocephalus, and the Arnold-Chiari malformation: reappraisal of theories regarding the pathogenesis of posterior neural tube closure defects. Neurosurgery. 1986;18:559-64.

2. Salman MS, Blaser SE, Sharpe JA, Dennis M. Cerebellar vermis morphology in children with spina bifida and Chiari type II malformation. Childs Nerv Syst. 2006;22:385-93.

3. Sutton LN, Adzick NS, Bilaniuk LT, Johnson MP, Crombleholme TM, Flake AW. Improvement in hindbrain herniation demonstrated by serial fetal magnetic resonance imaging following fetal surgery for myelomeningocele. JAMA. 1999;282:1826-31.

4. Wagner W, Schwarz M, Perneczky A. Primary myelomeningocele closure and consequences. Curr Opin Urol. 2002;12:465-8.

5. Scudder CA, Batourina EY, Tunder GS. Comparison of two methods of producing adaptation of saccade size and implications for the site of plasticity. J Neurophysiol. 1998;79:704-15.

6. Barash S, Melikyan A, Sivakov A, Zhang M, Glickstein M, Thier P. Saccadic dysmetria and adaptation after lesions of the cerebellar cortex. J Neurosci. 1999;19:10931-9.

7. Scudder CA, McGee DM. Adaptive modification of saccade size produces correlated changes in the discharges of fastigial nucleus neurons. J Neurophysiol. 2003;90:1011-26.

8. Desmurget M, Pelisson D, Urquizar C, Prablanc C, Alexander GE, Grafton ST. Functional anatomy of saccadic adaptation in humans. Nat Neurosci. 1998;1:524-8.

9. Straube A, Fuchs AF, Usher S, Robinson FR. Characteristics of saccadic gain adaptation in rhesus macaques. J Neurophysiol. 1997;77:874-95.

10. Waespe W, Baumgartner R. Enduring dysmetria and impaired gain adaptivity of saccade eye movements in Wallenberg's lateral medullary syndrome. Brain. 1992;115:1125-46.

11. Dennis M, Edelstein K, Hetherington R, Copeland K, Frederick J, Blaser SE, et al. Neurobiology of perceptual and motor timing in children with spina bifida in relation to cerebellar volume. Brain. 2004;127:1-10.

12. Thier P, Dicke PW, Haas R, Barash S. Encoding of movement time by populations of cerebellar Purkinje cells. Nature. 2000;405:72-6.

13. Thier P, Dicke PW, Haas R, Thielert CD, Catz N. The role of the oculomotor vermis in the control of saccadic eye movements. Ann NY Acad Sci. 2002;978:50-62.

14. Mclaughlin SC. Parametric adjustment in saccadic eye movements. Percept Psychophys. 1967;2:359-62.

15. Schweighofer N, Arbib MA, Dominey PF. A model of the cerebellum in adaptive control of saccadic gain. I. The model and its biological substrate. Biol Cybern. 1996;75:19-28.

16. Albano JE, King WM. Rapid adaptation of saccadic amplitude in humans and monkeys. Invest Ophthalmol Vis Sci. 1989;30:188393.
17. Deubel H. Separate adaptive mechanisms for the control of reactive and volitional saccadic eye movements. Vision Res. 1995;35:3529-40.

18. Salman MS, Sharpe JA, Eizenman M, Lillakas L, To T, Westall C, et al. Saccadic adaptation in children. J Child Neurol. (in press).

19. Salman MS, Sharpe JA, Eizenman M, Lillakas L, To T, Westall C, et al. Saccades in Children with Chiari type II malformation. Neurology. 2005;64:2098-101.

20. Dennis M, Fletcher JM, Rogers T, Hetherington R, Francis DJ. Object-based and action-based visual perception in children with spina bifida and hydrocephalus. J Int Neuropsychol Soc. 2002;8:95-106.

21. Van Allen MI, Kalousek DK, Chernoff GF, Juriloff D, Harris M, McGillivray BC, et al. Evidence for multi-site closure of the neural tube in humans. Am J Med Genet. 1993;47:723-43.

22. Fletcher JM, Dennis M, Northrup H, Barnes MA, Hannay HJ, Landry SH, et al. Spina bifida: genes, brain, and development. Int Rev Res Ment Retard. 2004;29:63-117.

23. Wills KE. Neuropsychological functioning in children with spina bifida and/ or hydrocephalus. J Clin Child Psychol. 1993;22: 247-65.

24. Dennis M, Fitz CR, Netley CT, Sugar J, Harwood-Nash DC, Hendrick EB, et al. The intelligence of hydrocephalic children. Arch Neurol. 1981;38:607-15.

25. Hunt GM. The Casey Holter lecture. Non-selective intervention in newborn babies with open spina bifida: the outcome 30 years on for the complete cohort. Eur J Pediatr Surg. 1999;9 Suppl 1:S5-8.

26. Mazur JM, Aylward GP, Colliver J, Stacey J, Menelaus M. Impaired mental capabilities and hand function in myelomeningocele patients. Z Kinderchir. 1988;43 Suppl 2 :S24-7.

27. DiScenna AO, Das VE, Zivotofsky AZ, Seidman SH, Leigh RJ. Evaluation of a video tracking device for measurement of horizontal and vertical eye rotations during locomotion. J Neurosci Meth. 1995;58:89-94.

28. SPSS Inc. SPSS (Statistical Package for the Social Sciences) for windows: Chicago, IL, 2001.

29. Altman DG. Practical statistics for medical research. London; New York: Chapman and Hall; 1995.

30. Hopp JJ, Fuchs AF. Investigating the site of human saccadic adaptation with express and targeting saccades. Exp Brain Res. 2002;144:538-48

31. Mezey LE, Harris CM. Adaptive control of saccades in children with dancing eye syndrome. Ann NY Acad Sci. 2002;956:449-52.

32. Robinson FR. Role of the cerebellum in movement control and adaptation. Curr Opin Neurobiol. 1995;5:755-62.

33. Straube A, Deubel H, Ditterich J, Eggert T. Cerebellar lesions impair rapid saccade amplitude adaptation. Neurology. 2001;57:2105-8.

34. Dennis M, Edelstein K, Frederick J, Copeland K, Francis DJ, Blaser SE, et al. Peripersonal spatial attention in children with spina bifida: Associations between horizontal and vertical line bisection and congenital malformations of the corpus callosum, midbrain, and posterior cortex. Neuropsychologia. 2005; 43:2000-10.

35. Hashimoto M, Ohtsuka K. Transcranial magnetic stimulation over the posterior cerebellum during visually guided saccades in man. Brain. 1995;118:1185-93.

36. Robinson FR, Fuchs AF, Noto CT. Cerebellar influences on saccade plasticity. Ann NY Acad Sci. 2002;956:155-63.

37. Coesmans M, Smitt PA, Linden DJ, Shigemoto R, Hirano T, Yamakawa Y, et al. Mechanisms underlying cerebellar motor deficits due to mGluR1-autoantibodies. Ann Neurol. 2003;53:325-36.

38. Huber-Okrainec J, Dennis M, Brettschneider J, Spiegler BJ. Neuromotor speech deficits in children and adults with spina bifida and hydrocephalus. Brain Lang. 2002;80:592-602.

39. Colvin AN, Yeates KO, Enrile BG, Coury DL. Motor adaptation in children with myelomeningocele: comparison to children with ADHD and healthy siblings. J Int Neuropsychol Soc. 2003;9:642-52.

40. Edelstein K, Dennis M, Copeland K, Frederick J, Francis DJ, Hetherington CR, et al. Motor learning in children with spina bifida: Dissociation between performance level and acquisition rate. J Int Neuropsychol Soc. 2004;10:1-11. 